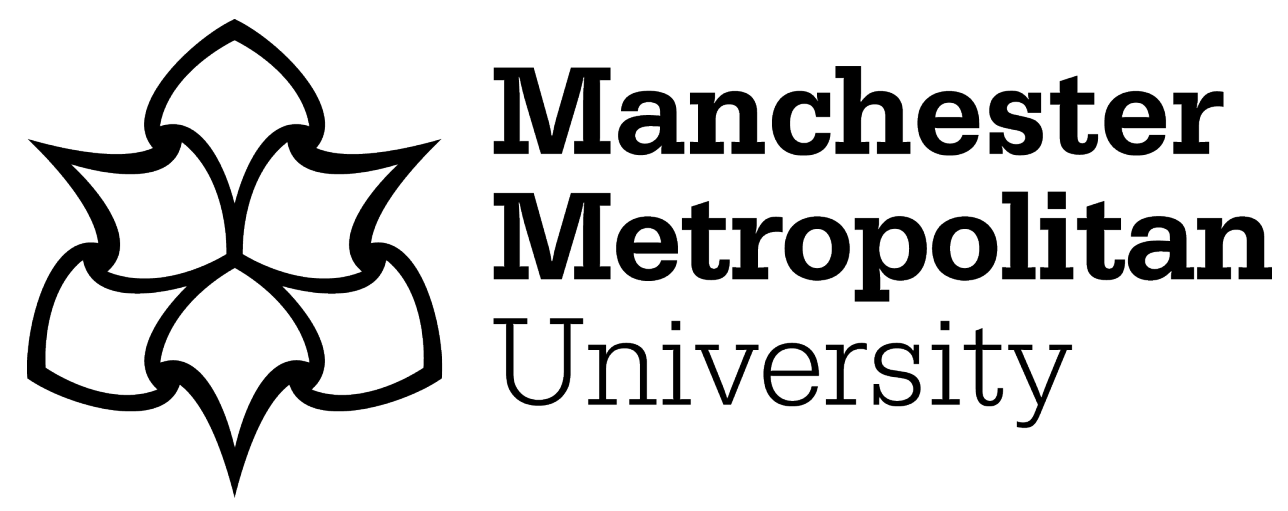

Bousfield, DE (2018) Face(t)s of self in interaction. Journal of Politeness Research, 14 (2). pp. 225-243. ISSN 1612-5681

Downloaded from: https://e-space.mmu.ac.uk/620370/

Version: Accepted Version

Publisher: De Gruyter

DOI: https://doi.org/10.1515/pr-2018-0014

Please cite the published version 
Derek Bousfield

Department of Languages, Information and Communications, Manchester Metropolitan University, Geoffrey Manton Building Rosamond Street West Off Oxford Road, Manchester, United Kingdom.

d.bousfield@mmu.ac.uk

\section{Face(t)s of self and identity in interaction}

\section{Abstract}

Combining (meta-) theoretical extension and practical application of models of politeness, the collected works of this special edition promise to make a significant and lasting contribution to the field as well as signalling an important milestone in interactional and pragmatics research more generally. Focussed to a greater or lesser extent on the 'impact' of the research on the social, occupational or legal world around us, the collected papers here are all in effect 'interventionist' (cf. Antaki 2011: 8). That is, the collected works of this special edition, whether dealing with remote interactions via a call centre (Jagodzinski and Archer, (this volume); Harrington, (this volume)) or face-to face interaction via an appraisal or a business meeting (Archer and Willcox, (this volume); Chan, (this volume)) and irrespective of the varying approaches to im/politeness they take, all contribute precisely to the need for further refinement, development and empirical study which Haugh (2018) wisely advocates in his recent appeal for metatheorisation in politeness work. To this end, this paper argues for the evident directions and potential applicability of future metatheorising for im/politeness research exploring and suggesting collocated consideration of notions of face, identity and politeness in a wider notion - in interactional studies - of 'self'. 
Keywords: applied research, face, identity, impact, impoliteness, interventionist, politeness, self.

\section{Introduction}

In this special edition of collected works we see an fascinatingly disparate set of approaches, analysing a diverse array of data, but all operating in a common enterprise: the empirical exploration and demonstration of what has come under the nomenclature of 'im/politeness research' applied to real-world settings. However such an observation doesn't go far enough either in terms of explaining the fundamentally crucial and milestone significance of the collection to the field in particular and studies of interaction across multiple fields more generally.

Haugh (2018) argues passionately for a metatheoretical turn in future im/politeness research - advocating the need to more closely and comprehensively view and assess what different and occasionally competing theories bring to the field of study in order to draw attention to areas that may be in need of further theoretical development (Haugh 2018: 153). This is not to say approaches to im/politeness do not or should not cover real-life data, they often self-evidently do and Haugh was clear on the importance of the role of empiricism in such (meta-) theorising. Rather, what is explicit or implicit in each of the papers here in this collection is the potential that the direct impact that the application of their findings - which includes theorising - can have in the real-world across a range of interactional activity types (Levinson 1992) rooted in business/occupational settings.

Despite being oft utilised, one area which requires further theoretical development and empirical study is the notion, construction and complementary-to-other models aspect of 
'face'. All the papers collected here consider and begin to extend the notion of face. Indeed, more than that, the papers - either explicitly or tacitly - discuss the concept of multiple aspects of face and how these aspects interrelate with the concept identity (cf. Arundale 2010) or identities (Joseph 2013). As I argue below, these multiplicities of face and face expectations, can be considered as facets of the self, having wider implications potentially well beyond the immediate interaction where they are co constructed. ${ }^{1}$ This understanding of face has long been understood; ever since Goffman's $(1955,1967)$ original exposition, but rarely extended and frankly often ignored. As such these aspects of face are explored here in terms of face expectations and face construction realities with both, along with an extension of understanding of identities, all being aspects of a wider theoretical notion of 'self'.

The field of im/politeness is firmly based on research borne out of empirical work: observation and analysis of interactional facework engaged in by participants in real situations and involving real world examples. Given its firm foundation from its founding roots in Variationist Sociolinguistics, the Interactional Sociolinguistics / Pragmatics fields now occupied with the area of study known as im/politeness has long had such an empirical scope. This said the development of an empirical foundation has been slow. Brown and Levinson (1987) provide us with a seminal work - which arguably effectively established the field. However this work is ultimately one in which the 'empirical' examples used to punctuate the arguments made are ones drawn out of a wider situational context (which is then backgrounded and arguably ignored). We do see a more comprehensively and situationally contextualised set of examples in later work on impoliteness (see Culpeper, Bousfield and Wichmann 2003; Bousfield 2007, 2008, for example), work which increasingly explores the phenomena under scrutiny in dynamic, fluid, and extended turns.

\footnotetext{
${ }^{1}$ The concept of construction in 'co-constructed' suggests a collaborative exercise requiring effort and collaboration towards a known and shared goal. Face can be 'co-constructed' in ways which can be identified as 'contested' or even 'aggressive' and 'adversarial' (See Bousfield 2008).
} 
All of which provide greater and deeper underpinnings for empiricism. Indeed, the empirical exploration of more widely, situationally and comprehensively contextualised work allows the identification and exposition of more sophisticated and nuanced modelling of the anatomies under which politeness and impoliteness are created and operate. All this is in line with Haugh's (2018) thesis on the future direction of research of this nature.

Haugh's thesis (2018) argues for a metatheoretic line and insists on a “...particular need of further theoretical development and empirical study" (2018: 153). The following bears repetition and the exposition of the logical outcomes it allows: Empirical study allows for refinement of models and theories of the metatheoretic type Haugh suggests. I would offer one word of caution, however. Whilst it is always good to strive for greater refinement which the call for metatheory suggests, another over-dependent sojourn - similar to the ultimately ill-fated drive for the anti-theoretic 'relational work' approach - essentially risks the entire field. To lapse, once again, into unfettered academic navel gazing with an over focus on 'metatheory' - in effect arguing repeatedly over what the terms themselves mean both to academics and lay users of language - would be a dangerous move. It would be a move made against the backdrop of a world and of research funding systems increasingly impatient for results, critical of the presumed value of research, and sceptical of the actual or potential applicability of much Humanities and Social Science findings. When even academic researchers in our own field consider what we do in im/politeness research as "mostly harmless" (O'Driscoll, personal communication), then we need to take a long, hard, and potentially uncomfortable look at ourselves, and at (i) the value we bring, (ii) what we recognise that we bring; and, crucially, (iii) that which we seek to bring to society for the time, treasure, and resource we take in order to continue to engage in the sorts of research in which we engage. 


\section{Not only, but also.}

The pursuit of knowledge for its own sake remains something in which I believe passionately. Yet if, following the authors of this collection of works, we can also do more: where our research and research findings not only discover new knowledge about us all and the social world we have collectively created for ourselves, but also has an impact in bettering our interactions within that social world, then this is what we should also strive for. Consider the points made in Archer and Jagodzinski (this volume) - the papers in the present collection all advocate not only for greater dialogue between academics themselves, but also for dialogue and cooperation between academics and professional practitioners across a range or representative sectors and industries such as call centre call handlers (Jagodzinski and Archer, Harrington (this volume)), business negotiations (Chan, (this volume)) and performance appraisal and management situations (Archer and Willcox (this volume)). Each paper, in its own way, shows the gestalt fusion of cutting edge academic research and theorising with long-term evolutionary and culturally sensitive business and professional practice. Each paper, it its own way, intervenes (following Antaki 2011, as mentioned above) or rather has impact and effect, offers promise, clarity and direction for future real-world activities and interactions.

We should embrace such moves for two fundamental reasons: (1) real-world benefits and results, and (2) (meta-)theoretical extensions, and refinements to our theoretical modelling as a result of the real-world benefits and results. Theory, and further theorisation based on empirical observation has a key role to play, of course. But we must start with the uncomfortable question - what, precisely, have the vast majority of research monographs, and papers, lectures and plenaries on im/politeness given back to the society that support that research? We can readily recognise that it is vast amounts indeed. However the explicitness of those benefits, of the impacts on society, are arguably more fully to be seen crucially by 
members of society outside of academia who may not know or recognise what we do as being relevant to them and their fields and areas of interest.

Our work should not only be empirically grounded in observation leading to (meta)theoretical extension and enhancement, but should also be explicitly applied, and have impact, the results of which - carefully and ethically acquired - should be empirically handled and fed back to further refine the metatheorising and future enhancements that Haugh (2018) correctly calls for. We can therefore join the empirical with the theoretical to forge a future line of research which is continually enhancing and testing the models but which, crucially, becomes what Antaki termed (I would argue unhappily for us here) as 'interventionist' ${ }^{\text {'2 }}$ (Antaki 2011: 8). It behoves us to do so especially given we have the knowledge, the approaches (if still contested) and the models of explanation and evaluation.

To those that would still baulk at the prospect of the application of (contested) models or approaches to train and prepare occupational participants in anticipating, recognising, accounting for, predicting, and dealing with behaviours that the field understands (broadly) as being captured under 'im/politeness', I would merely offer the following analogy: The semantic concepts of "table" and "chair" are long contested as interesting, intellectuallystimulating exercises in semantic definitions, and philosophical ruminations. Defining and differentiating "table" with, and from that of "chair" is problematic. Both can have three legs, or four, or even more. The vast majority of both can be sat upon quite safely, though the expectation is the latter would be used for this purpose rather more than the former. We could spend - as many a class in linguistics and philosophy has - discussing the definitions based on use, and as such we are likely to resolve the discussion on definitions and differentiation

\footnotetext{
2 The concept of "intervening" suggests taking a controlling role in those real-world interactions for which our research and research findings can offer support and contributions, hence a term more akin to 'contributionist' might be in order.
} 
by utilising a prototype approach (Coleman and Kay 1981) to understanding the semantic differences and definition (though in doing so we may still not please all theorists in the classroom at the time).

Whilst we are discussing, and seeking to resolve this (meta-)definitional conundrum, families, friends, and individuals, all across the world, are calmly and quietly utilising without much theoretical angst in doing so - their own tables and chairs. They are occasionally purchasing others when the need arises and looking for the best sets of tables and chairs that functionally and aesthetically fit their needs and wants. Indeed, what fits the need for one family, individual, business or organisation may not be the best model of table or chair for another family, individual, business or organisation. Their choice will probably be based also on one of conventionalised expectation as to what model of table and chair best suits the wider environment in which they will be utilised - and individuals are likely to put in little metatheoretical thought when actually using the furniture and are likely to feel disadvantaged if the furniture is not available as a result of manufacturer wrangling over terms and construction delaying the delivery and therefore the usefulness of such items.

If we now assume the analogous concepts of "table" and "chair" are replaced with "im/politeness" and "interaction" we should see the analogy and the logical implications. Those in the wider world outside of academia are hardly likely (to be content to) wait around for the evolution of the table and chair perfectly suited to their needs, preferring to utilise the functional versions they already have until need or aspiration motivates them to seek out new versions (ones which, incidentally, their needs contribute to in terms of design and functionality). So too is this true for the models of im/politeness and interaction we have long been theorising based on empirical evidence borne out by observation and evaluation. Whilst many of the empirically generated models could be readily applied to work-based, social and legal interactions (see below), relatively few are or have been. The kinds of research we have 
produced on phenomena we have collectively termed or at least understood to be 'im/politeness' are those that Haugh (2018) notes lends themselves to interdisciplinary scrutiny. Hence, it is our time to shine. Our academic practice can be applied to enhance (or supplant and replace) new or existing models of policies and practice of interactional behaviour in myriad occupational, social and legal settings. Currently such settings, where they draw from academic models and theorising tend to rely on psychological or sociological models at best; or impressionistic approaches borne out of a reading of the law (see the argument under section 8 , below) or social custom and practice but with no structure or objectivity at worst.

\section{Recent and Upcoming Theorising}

Until relatively recently, most research on im/politeness has been of the following linear format captured in simplified, abstract form in Figure 1, below. This figural abstraction represents the traditional model of empirically grounded observation and evaluation. One leading to desk or lab based (meta-) theorising as to both "how" and "why" things observed happen; and moving, at most, to the modelling of the observed operations based on such empirical observation. In many cases this situation would be repeated with academic colleagues in the field in question, taking the theories and models created, and in empirically testing them on new data sets in fields where the models had never been theorised before refining such models.

$<$ Place Figure 1 about here $>$

Figure 1. Empirical Research (in Im/Politeness) 

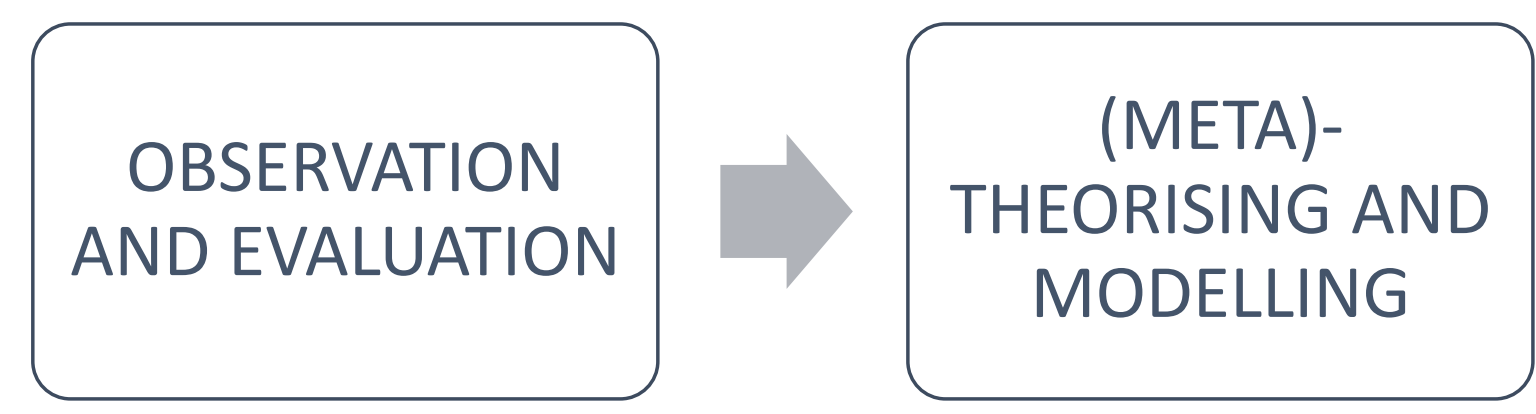

The papers outlined here in this special collection, however, are adding to a relatively small ${ }^{3}$ but rapidly growing number of others in applied humanities and social science research with real-world impact. This approach seeks to follow the following format as captured under the abstraction represented in Figure 2.

$<$ Place Figure 2 about here $>$

Figure 2. Empirical-Applied Research (in Im/Politeness)

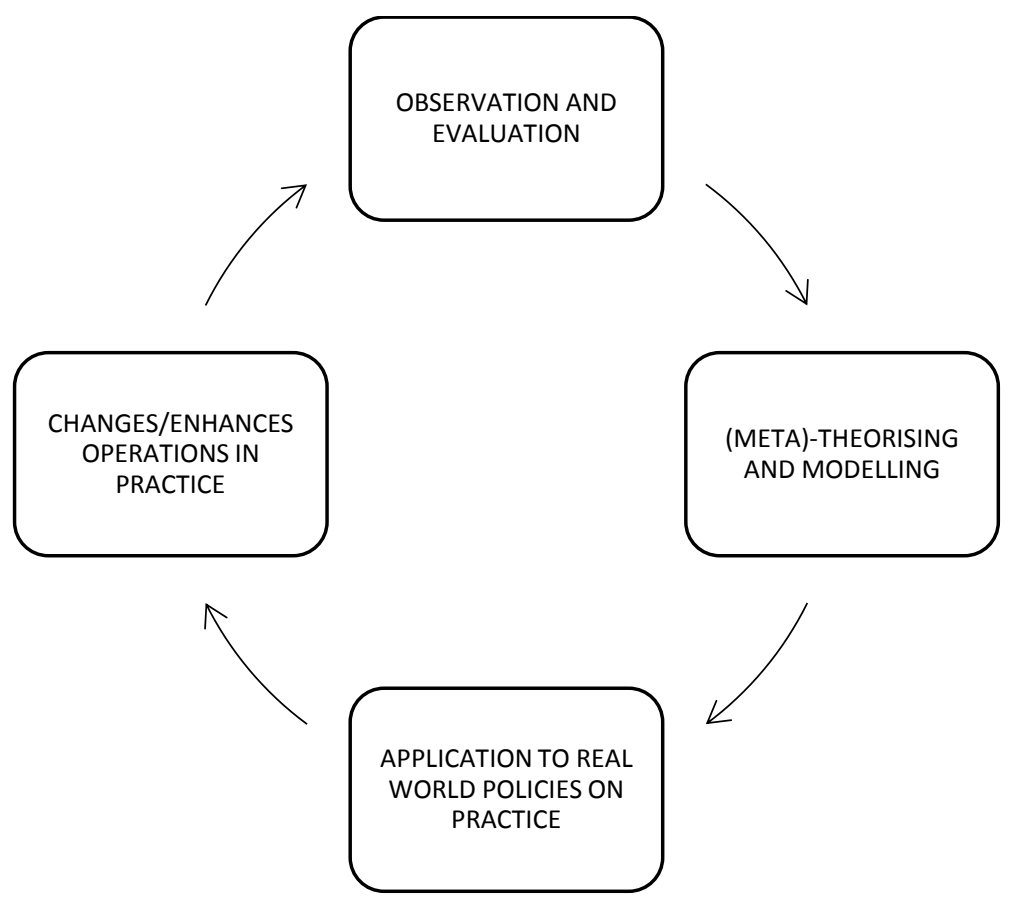

\footnotetext{
$3^{3}$ '...relatively small...' being relative both to (i) the volume of empirical research papers on im/politeness, and (ii) when compared to STEM subjects - the real-world applicability of a higher proportion of research being more readily apparent and easier to operationalise.
} 
Here in figure 2 we can see and understand how such works clearly retain the vital and necessary empirical observation and evaluation - evaluation here being understood as "why we should care about what we are seeing" - leading, as in Figure 1, above, to (metatheorising and modelling of the phenomena observed and evaluated. The purpose of such modelling has always implicitly included the possibility of others - not just those within the academy, but far beyond - taking up our work and utilising it for the benefit of other stakeholders across society. Archer and Willcox (this volume) are especially explicit in this regard, and we can therefore expect further work by Archer and Willcox, and Willcox and Archer to be forthcoming in the not too distant future given the promise of application of their findings which they make in their paper (ibid). Hence Figure 2 includes the next stage for applied humanities and social science research which is the application of the theories and models to real world policies and practices which then (most likely, given what is argued below in section 8 on social and legal approaches to 'im/politeness') when enacted, give (ideally) enhancements to interactional operations in practice. The outcomes of these changes/enhancements to operations in practice, however, must be constantly scrutinised or observed and evaluated for their efficacy and hence, the entire process is cyclical and circular in an ever virtuous ever empirical circle of refinement and application.

We can see this in the papers gathered together in this special edition. All, to a greater or lesser degree have empirically observed and evaluated models and approaches to $\mathrm{im} /$ politeness and all have observed extenstions to the immediately present theoretical ground accounting for 'face' (Goffman 1967).

\section{Face}


Theorised as the presentation of self in everyday life - face has always been seen as:

... the positive social value a person effectively claims for himself by the line others assume he is taking during a particular contact. Face is an image of self delineated in terms of approved social attributes - albeit an image that others may share, as when a person makes a good showing for his profession or religion by making a good showing for himself.

(Goffman 1967: 5).

This is the core quotation which is regularly deployed to introduce the concept of face in academic theorising. However, this explicit definition and explanation of face has elements which are arguably often ignored (such as those elements regarding 'profession' and 'religion') in the application of the concept in academic theorising and research publication. However, we humans readily identify with, and construct expectations of who we are as people by such notions of 'profession' and 'religion'. Indeed, these critical elements of a notion of our identities or selves are but two examples of what we might recognise as social/cultural organisations in and through which we metonymically invest expectations of face and, consequently (see below) identity and self). Precisely because elements such as these which were introduced by Goffman have been often ignored, they have been rarely explored, interrogated and challenged in later theorising and application. Hence this, the original academic expression of the concept of face, encapsulates fundamentally underexplored concepts of 'positive social value', 'self', and 'approved social attributes' all of which would benefit from further empirically grounded (meta-)theorising.

Indeed, of these concepts which Goffman (ibid) introduces, some elements ('positive social value', and 'approved social attributes') are potentially problematical to a field more recently having turned to study conflictive (Culpeper 1996, Bousfield 2008) as well as 
associative (Leech 1983, 2007) and accommodative (Brown and Levinson 1987) modes of interaction. Hence the notions of "positive" and "approved" in co-created instances of linguistic and verbal aggression become intriguing and contested areas of (meta-)theoretical work leading from, and potentially back to greater empirical understanding and application.

\section{Of face and face expectations: schemata.}

The importance of face in accounts of interactive communication is widely seen. Scollon and Scollon argue that there can be no interaction without face being an issue (Scollon and Scollon 2001). Terkourafi (2008) is one colleague who argues convincingly that it is only in interaction that face exists. However, as clearly and explicitly noted by Archer and Willcox (this volume) face, and anticipation of how it will be co-constructed does not, indeed cannot exist in a decontextualized interaction. Precedent or past-experience, and assumptions of context, participant positions, roles and responsibilities, along with relative notions of power all give rise to expectations of face in interaction even before the interaction begins to unfold. The logical corollary of this, then, is that 'face' is at least partly based on pre-existing face expectations which, themselves, I would argue are schematic.

If we accept that there are face expectations then we have clearly stepped into the world of 'frames' or 'schemata' as understood in terms of 'top down' theorising. Culpeper (2001: 75-6) explains how we do this by summarising work on cognition and suggesting the categories that we apply in our perceptions of other people. These (ibid) fall into three groupings: Personal Categories, Social-Role Categories, and Group Membership categories. Culpeper (ibid) explains that each of these categorical groupings have further sub-categories within them, like so:

PERSONAL CATEGORIES (including Habits, Interests, Traits, Goals) 
SOCIAL ROLE CATEGORIES (including Kinship, Occupational and Relationship roles)

GROUP MEMBERSHIP CATEGORIES (including the classic sociological categories of age, generation, sex or gender, religion, social class, nationality, region of origin, etc.)

Whilst Culpeper (2001) was creating an interdisciplinary understanding by drawing from then emergent work in psychology for how we read others (and he was doing so, primarily as he was then ostensibly interested in applying these categories to the processes of characterisation in drama), it should be apparent - given the human capacity for selfreflection and origo-shifting - that we can apply these (sub-)categories to ourselves, too. This should be especially true when we apply these sub-categories to our socio-cultural understandings, or 'Barthesian’ (Barthes 1957) 'Myths'. Barthesian Myths being those stories or narratives which members of a society tell themselves to understand some aspect of nature or reality, including how (under the processes of self-reflection and origo shifting) society-atlarge views the very sub-categories to which we may belong, above. The categories in Culpeper's (2001) taxonomy are, in effect, aspects of identity, or rather they are composite parts, in context, of the multiplicity of identities we have and enjoy (and all of them are 'Myths' in the sense they are socially and culturally constructed narratives or understandings). Joseph (2013: 36), by way of explanation, argues that:

Identity relates classically to who individuals are, understood in terms of the groups to which they belong, including nationality, ethnicity, religion, gender, generation, sexual orientation, social class and an unlimited number of other possibilities.

(Joseph 2013: 36, cited in Bousfield 2013: 41. See also Tajfel 1978 and GarcesConejos Blitvich 2013)) 
When we consider the Group Membership Categories from Culpeper (2001) comparing them to Joseph's list of classic features of identity - the relationship is clear: Culpeper's categories constitute elements of identity - both of others and of ourselves. While these may contribute to expectations of ourselves, Joseph (2013: 38) goes on to argue that we all have not one identity, but rather a multiplicity of identities:

[...] if only because everyone we encounter constructs an identity for us, based on whatever indices they interpret us as projecting, whether or not we are aware of projecting them.

(Joseph 2013: 38).

These indices must be based, at least, in part in Culpeper's (2001) categories and subcategories, and identity (co-) construction can arise out of partial or happenstance observation of the indices projected.

For example: the blonde lady with the kindly face and the cornucopia of armfuls of evidently important papers currently sitting across from me on the train as I type this section of the draft of this paper smiled warmly at me as she struggled into her seat. I suspect she did so mostly as I offered assistance in holding her papers as she wrestled bravely with her oversized umbrella, and exceptionally shiny if impractical bag whilst in the process of sitting down on the sole unoccupied seat on a packed commuter train. Further, I had happily moved my laptop to facilitate her placing her papers down on the shared table too. We each -never having met one another other before- have in Joseph's terms then, begun to construct identities for each other based on traits (I appear to be kind and helpful in assisting a fellow passenger) and goals (I appear to wish to assist a fellow passenger) given, at least, elements of personal categories (Culpeper 2001: 56-7). We have not only (co-)constructed our identities at that moment, but continue to do so. As I type this line, her scattered pile of 
papers forgotten, her umbrella pressing uncomfortably against my leg under the table, she administers eyeliner from her Revlon contour kit with the precision of a battlefield medic engaging in emergency surgery, doing so all while as the train bounces across junction tracks as we head into Manchester's Oxford Road station. I am beginning to round out - rather impressionistically - an identity for her based on our brief interaction and my subsequent observations of the behaviours and indices she is projecting. The same is true in return - she had been glancing up at me from her papers as I typed, paused, stared out the window momentarily lost in contemplation as to how to frame the next line, before I plunged back in with furious levels of typing. I suspect I'd also projected what I'd like to think of as brooding expressions of intellectual contemplation punctuated by 'Eureka!' emotional facial expressions, but which may come across somewhat differently to those observing them.-Such multi-modal behaviours - including linguistic ones - are effectively 'bottom up' (cf. Culpeper 2001) behaviours operating out of this loose interaction, but are all mapped back against our pre-existing, schematically held knowledge which is then compared against the Barthesian myths we hold about ourselves and our social world.

I can further add, since closing my laptop to disembark from the train, I noticed that amongst her armfuls of papers were secondary school level examination papers that she spent some time reading and making notes upon. She is evidently an educator (under Social Role categories Culpeper 2001), or at least is involved in one of the examining boards. My observationally fuelled presumptions of her kindly face, affinity for makeup and extreme skill in applying it, blonde highlights growing out of brown hair, smart-casual attire, and the identity created from these traits and behaviours as 'indices' that she is projecting - coupled with the Barthesian Myths (and connotations and values associated with them), are further shaped by the observation of her as involved in education. 


\section{Identity or identities?}

The identity (co-) constructed (if unwittingly) of the kind-faced, steady-handed, blonde educator is clearly not the only one my fellow passenger from this morning has. As Joseph notes:

... there are countless versions of you out there in the minds of others, each different from the persona you imagine for yourself. Because everyone brings their own experience of life, and of reading other[s] to bear ... in interpreting the identity of those we meet.

(Joseph 2013: 38).

We might consider, from Joseph's line here, that there are external versions of identity (coconstructed in interactions like mine and the blonde educator's on the train), and internal versions (based on the persona you imagine for yourself) of identity. Each version of identity is informed by the schematic categories and sub-categories Culpeper (2001: 75-6) identifies above, and refined, challenged or confirmed by the linguistic and multi-modal behaviours observed, mapped against the social Myths (Barthes 1957) of "reality" we accept (unwittingly or otherwise) and share once enculturated by our host societies and cultures. The significance of this, and how identities operate and can be shaped or changed as a result is seen in the concept of 'face' (which is in turn co-constructed through interaction, a staple of which is, again, most often via language behaviour).

As has been argued elsewhere (see Bousfield 2013; McIntyre and Bousfield 2018), taking a line from Goffman (1967), Joseph (2013) and Tajfel (1978) (amongst others) Face is punctual, Identity is durative. This recognition leads us to the conclusion that face - being in construction or creation only in interaction, is nevertheless expected, and in the reality of coconstruction, a longer term influence on the much more long-standing, and theoretically 
slower to change (under normal circumstances) identity - hence the concept of identities being durative. However, identities may be durative, but they are not perfectly durable. Constant and repeated constructions of face in certain ways - whether expected or unexpected; positive or negative, can give rise to changes to identity/identities (see Burnett and McCrindle 1999, and Loh et al. 2010, for example on the long term effects of verbal abuse on family members). These are changes which in turn I contend can give rise to changes of future face expectations (based on what has passed into long term schemata). Collectively, then, face, face expectations, face construction realities, and identity/identities are in a symbiotic if sometimes uneasy relationship, and all are more or less dynamic or at least malleable facets of a wider sense of 'self' and self-esteem; the relative organisation of which can be seen in the simplified diagram in Figure 3.

Figure 3. Self, Identities and Faces.

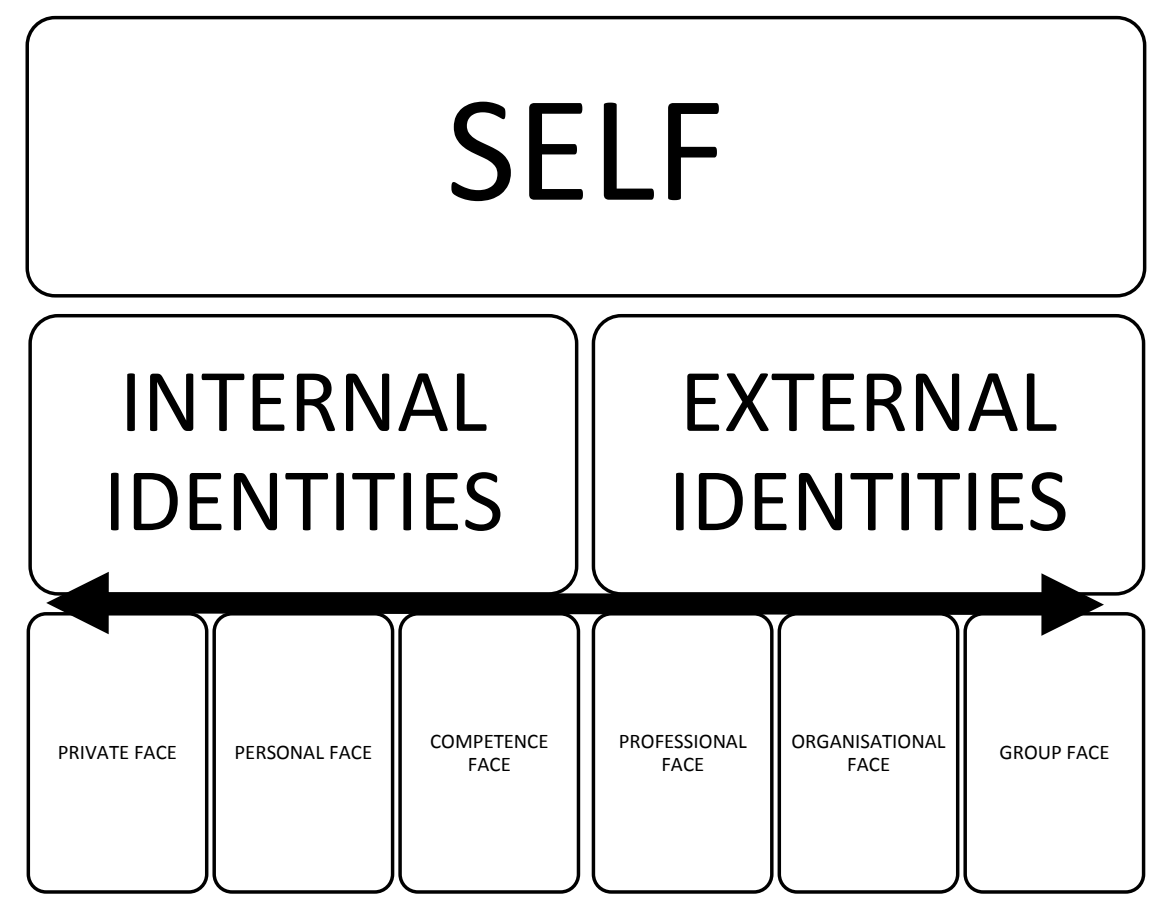


Figure 3 outlines the (oversimplified) relationship between those internal and external identities (outlined as a corollary of Joseph's position, above) and the different varieties of face (in both expectation and interactional reality).

Both internal and external identities, being durative, would more closely map onto Culpeper's (2001) categories as explored above. Those aspects of face, being punctual, and hence only in operation once in interaction, would more closely map onto those aspects of "bottom up" or "data driven" readings we, as lay users in interaction, glean from the interaction and those participating within it given the linguistic (and other) behaviours in which they engage. The internal and external identities we have, whichever is most relevant in any given contextualised interaction - precisely because they are durative, (and hence exist outside of interaction in our own minds, and in the minds of others) are what give rise to face expectations. When expectations of face co-construction do not match the interactional realities of face co-construction that we experience, then this can provide fertile ground for disagreement, insults, verbal abuse and other forms of violence through what has otherwise been termed "loss of face" - which is in effect, loss of face against the expectations of that face. Face, of course, as determined by Jagodzinski and Archer (this volume), and Archer and Willcox (this volume), can include personal, competence, professional, organisational, and group varieties. We might also conclude private and public versions of face exist, too given their more obviously durative 'identity' counterparts evidently exist. And face, as we have argued above (and in Bousfield 2013) is one primary route into identity construction, malleability and change.

No more so can the arguments made in the previous sections above be demonstrated (and the potential future benefits of re-application of our arguments, models and theories back to the wider world) than in Social, Occupational and Legal approaches to ‘im/politeness’, below. 


\section{Social, Occupational and Legal Approaches to 'Im/Politeness'}

We have long understood that Im/Politeness is, at best, a second-order term (cf. Eelen 2001) for first order understandings of linguistic and other actions. Concepts such as 'verbal abuse' (Loh et al 2011, Manderino and Berkey 1997), 'verbal aggression' (Archer 2008, Hamilton 2011), 'agreeableness' (Krisjansson 2006), 'civility’ (Bannister and O’Sullivan 2013, Boyd 2006, Edyvan 2017), 'incivility’ (Smith et al. 2010), 'manners' (Buss 1999, Carter 1998, Levy 2010), 'rudeness' (Terkourafi 2008), ‘impoliteness' (Culpeper 1996, 2011; Bousfield 2008), 'politeness' (Brown and Levinson 1987) are not only all captured under the term Im/Politeness (or '(im)politeness'), but are also concepts (if not the (meta-)theoretical terms) recognised under various legal and social codes of behaviour and interactional constraints. Such codes of behaviour and constraints include those around concepts such as 'violence' which includes, tacitly or explicitly verbal violence or non-physical, verbal threats. The United Kingdom's National Health Service explicitly considers violence as including verbal abuse or harassment. Further, the UK's Health and Safety Executive (HSE) defines violence as including both 'physical assaults' and 'threats'. For 2015/16 (the last year of available data) Buckley (2017: 2) notes that 1.4\% of working adults in the UK were victims of one or more incidents at work. This amounts to 350,000 adults of working age experiencing work related violence in many more incidents. Indeed, he notes " 698,000 incidents of violence at work...comprising 329,000 assaults, and 369,000 threats.” (ibid)

Where we have covered such behaviours as im/politeness and facework theorists and researchers, our main focus has been on the latter that of 'threats', whether in exploring politeness and the attendance to potential 'Face Threatening Acts (see Brown and Levinson 1987), or the response to such acts in impoliteness modelling (see Bousfield 2008, Culpeper 2011). 'Threats' therefore fall squarely if broadly under the area we research in 'im/politeness'. The UK's laws, which outline proscribed behaviours and legal sanctions and 
repercussions as a result prohibit verbal violence, aggression, insult (though see below), or harassment across a range of legal acts. These acts include the Violence at work act 2003; the Public Order Act 1986; Public Order and Justice Act 1993; Protection from Harassment Act 2007, the Justice Act 2007 and, but not limited to the Crime and Courts Act 2013. These laws have informed various Scottish Government (2009), and UK Home Office (2003) initiatives to challenge and combat such behaviours when they are seen to arise.

\section{Why should we care?}

There has been a movement within the United Kingdom which sought to overturn the laws relating to the giving and taking of offence around 'insulting', such as those above. Seeing it as a "price worth paying" in a free and open society, with freedom of speech enshrined at its core, ReformSection5 was a campaign to have section 5 of the Public Order Act 1986 reformed. The campaign succeeded, and the change exists in Section 57 of the Crime and Courts Act 2013 which came into effect on 1 February 2014 - the essential change was to remove the word insulting, but retain the wording of abuse (and the concept in verbal terms).

Given recent debates in the UK surrounding freedom of speech, a logical argument identical to that which focussed on the contested nature of "insult", could also centre on the concept of verbal abuse, too. After all, "abuse" - in its verbal form - is a term that is just as contested as any other. However, if left unchecked logic dictates that verbal abuse, and threats can become physical violence either as an extreme summative move; or as a response to the receipt of verbal abuse and threats. The UK's Health and Safety Executive (2017) still consider 'violence' to be definitionally inclusive of serious or persistent verbal abuse - which the HSE identifies can add to stress or anxiety. They (ibid) refer to the National Audit Office (NAO) report in 2003 which demonstrates a clear link between such forms of (verbal) 
violence and verbal aggression on the one hand, and staff sickness, turnover, and lost productivity on the other. The need to proactively deal with such situations as when (verbal) violence can and does arise is clear. Further it is clear right across current political and economic realities of much of the world. The need for resolution for unfolding situations involving verbal violence is borne out by pragmatics research, too. Wee (2004) writing on Extreme Communicative (non-verbal acts of self-harm as a form of protest) Acts (ECAs) theorised that communicative acts rarely, if ever, start out as "extreme", but rather, start small and become more extreme over time if satisfactory resolution of one sort or another is not achieved. The extension of ECAs to persistent cases of verbal abuse -either as a corollary extension, or response to it- is not too difficult to imagine and is implied in the HSE (2017) and NAO (2003) reports. Indeed under such research as identified by the NAO, and Wee's (2004) argument of the potential for ECA escalation, we simply cannot ignore the longer term negative personal, individual or social effects of 'impoliteness' given the impact it can have. The loss of trust and confidence in an organisation that a disgruntled colleague/client/customer/patient can acquire as a result of verbal violence is avoidable. Furthermore, loss of trust and confidence can be (at least partly) rectified with reactive responses and repair work or abrogated by introspection of process and procedures, and proactive action to prepare for, and avoid, face-threatening conflict scenarios (see Jagodzinski and Archer; and Harrington, this volume).

\section{Conclusion}

What is worth noting, here, in conclusion is that the legal and advisory documentation, above, covers a lot of detail on consequences of, and reporting of violence. Much less is covered, however, on a local response, and even less on proactive disarmament before such verbal 
violence starts. This is ironic, as Brown and Levinson (1987) were the first to theorise that politeness is at the heart of 'diplomatic language' and must surely be the protocol for it. They concluded that even if their model were not to be deemed the most refined or best model in al situations, theirs would be the sort of model which best explains the concepts covered. More than 30 years later after much (meta-)theorising about the concepts of im/politeness and how they should be modelled, we now see something of a return to Brown and Levinson inspired approaches - and all the while throughout those past three decades we have still needed those analogous tables and chairs. Further understanding, via metatheorisation is crucial, but dissemination of the current state of the art is not only possible, but key. It is key, not only to the continued thriving of the field, and the future of the study of interaction, but the health and welfare of a society which - whilst we all still have each other - will inevitably result in the proactive need for disarmament of the potential for (verbal) violence (cf. 'Politeness' in anticipating potential threats to face); and the reactive disarmament once that potential has been realised in action (cf. 'responses to Impoliteness'). 


\section{References}

Antaki, Charles. 2011. Six kinds of applied conversation analysis. In Charles Antaki (ed.), Applied conversation analysis, 1-14. London: Palgrave.

Arundale, Robert. 2010. Constituting face in conversation: Face, facework, and interactional achievement. Journal of Pragmatics 42. 2078-2105.

Archer, Dawn. 2008. Verbal aggression and impoliteness: Related or synonymous? In Derek Bousfield and Miriam Locher (eds.) Impoliteness in Language: Studies on its Interplay with Power and Theory in Practice, 181-209. Berlin: Mouton de Gruyter.

Archer, Dawn and Phil Wilcox. (this issue). The faces at play in performance appraisals: with a focus on UK retail organisation. Journal of Politeness Research: Language, Behaviour, Culture.

Bannister, Jon and Anthony O'Sullivan. 2013. Civility, Community Cohesion and Antisocial Behaviour: Policy and Social Harmony. Journal of Social Policy 42 (1): 91-110.

Barthes, Roland. 1957. Mythologies. New York: Hill and Wang.

Bousfield, Derek. 2007. Beginnings, middles and ends: a biopsy of the dynamics of impolite exchanges. Journal of Pragmatics 39 (12): 2185-2216.

Bousfield, Derek. 2008. Impoliteness in Interaction. Amsterdam: John Benjamins.

Bousfield, Derek. 2013. Face in conflict. Journal of Language Aggression and Conflict 1 (1): $37-57$.

Bousfield, Derek and Dan McIntyre. Accepted and Forthcoming 2018. Creative linguistics impoliteness as aggression in Stanley Kubrick's Full Metal Jacket. Journal of Literary Semantics.

Boyd, R. 2006. The Value of Civility? Urban Studies 43 (5-6): 863-878. 
Brown, Penelope and Stephen C. Levinson. 1987. Politeness: Some universals in language usage. Cambridge: Cambridge University Press.

Buckley, Paul. 2017. http://www.hse.gov.uk/statistics/causinj/violence/violence-at-work.pdf $<$ accessed 22 $2^{\text {nd }}$ March 2018>.

Burnett, Paul C. and Andrea R. McCrindle. 1999. The relationship between significant others' positive and negative statements, self talk and self-esteem. Child Study Journal 29 (1): 39-48.

Buss, S. 1999. Appearing Respectful: The Moral Significance of Manners. Ethics 109 (4): $795-826$.

Calhoun, C. 2000. The Virtue of Civility. Philosophy and Public Affairs 29 (3): 251-275.

Campbell, B. 1989. When words hurt: Beware of the dangers of verbal abuse. Essence 20 86.

Carter, SL. 1998. Civility: Manners, Morals, and the Etiquette of Democracy. New York: Basic Books.

Coleman, Linda and Paul Kay. 1981. Prototype Semantics: The English Word Lie. Language 57 (1): 26-44.

Chan, Angela. (this volume.) Exploring face, identity and relationship management in disagreements in business meetings in Hong Kong. Journal of Politeness Research: Language, Behaviour, Culture.

Culpeper Jonathan. 1996. Towards an anatomy of impoliteness. Journal of Pragmatics 25 (3): $349-367$.

Culpeper, Jonathan. 2001. Language and Characterisation. People in Plays and Other Texts. Harlow: Longman. 
Culpeper, Jonathan. 2011. Impoliteness: Using language to cause offence. Cambridge: Cambridge University Press.

Culpeper, Jonathan., Derek Bousfield and Anne Wichmann. 2003. Impoliteness Revisited: The special reference to dynamic and prosodic aspects. Journal of Pragmatics 35 (1011): $1545-1579$.

Edyvane, Derek. 2017. The Passion for Civility. Political Studies Review 15 (3): 344-354.

Eelen, Gino. 2001. A critique of politeness theories. Manchester: St Jerome Publishing.

Garces-Conejos BLitvich, Pilar. 2013. Face, identity and im/politeness. Looking backward,moving forward: From Goffman to practice theory. Journal of Politeness Research: Language, Behaviour, Culture 9 (1): 1-33.

Goffman, Erving. 1955. On Face-work. An analysis of ritual elements in social interaction. Psychiatry 18 (3): 213-231.

Goffman, Erving. 1967. Interaction Ritual: Essays in Face-to-Face Behaviour. Chicago: Aldine.

Hamilton, Mark A. 2011. Verbal Aggression: Understanding the Psychological Antecedents and Social Consequences. Journal of Language and Social Psychology 31 (1): 5-12.

Harrington, Leigh, (this volume.) "Helping you to pay us": Rapport management in debt collection call centre encounters. Journal of Politeness Research: Language, Behaviour, Culture.

Haugh, Michael. 2018. Theorizing (im)politeness. Journal of Politeness Research: Language, Behaviour, Culture 14 (1): 153-165. 
Health and Safety Executive. 2017. Violence At Work, 2015/16: Findings from the Crime Survey for England and Wales from RIDDOR. Health and Safety Executive: http://www.hse.gov.uk/statistics/causinj/violence/violence-at-work.pdf

Home Office. 2003. Respect and Responsibility - Taking a Stand Against Anti-Social Behaviour. Norwich: The Stationery Office.

Jagodzinski, Piotr and Dawn Archer. (this volume.) Co-creating customer experience through call centre interaction: Interactional achievement and professional face. Journal of Politeness Research: Language, Behaviour, Culture.

Joseph, John. 2013. Identity work and face work across linguistic and cultural boundaries. Journal of Politeness Research: Language, Behaviour, Culture 9 (1): 35-54.

Kristjánsson, K. 2006. Agreeableness. Journal of Value Inquiry 40: 33-43.

Leech, Geoffrey. 1983. Principles of Pragmatics. London: Longman.

Leech, Geoffrey. 2007. Politeness: is there an East-West divide? Journal of Politeness Research: Language, Behaviour, Culture 3 (2): 167-206.

Levinson, Stephen C. 1992. Activity Types and language. In: Paul Drew and John Heritage (eds.). Talk at Work: Interaction in Institutional Settings, 66-100. Cambridge: Cambridge University Press.

Levy, J. 2010. Multicultural Manners. In: Seymour, M (ed.) The Plural States of Recognition, 61-77. Houndmills: Palgrave.

Loh, Jennifer., Flora Calleja and Simon Lloyd Restubog. 2010. Words that hurt: A qualitative study of Parental Verbal Abuse in the Phillippines. Journal of Interpersonal Violence 26 (11): 2244-2263. 
Manderino, Mary A., and Neva Berkey. 1997. Verbal Abuse of staff nurses by physicians. Journal of Professional Nursing 13 (1): 48-55.

O’Driscoll, Jim. Personal Communication.

Scollon, Ron and Suzanne Wong Scollon. 2001. Intercultural Communication: A Discourse Approach. Oxford: Blackwell.

Scottish Government. 2009. Promoting Positive Outcomes: Working Together to Prevent Antisocial Behaviour in Scotland, Volumes 1 and 2, Edinburgh: Scottish Government.

Smith, P., Phillips, TL., King, RD. 2010. Incivility: The Rude Stranger in Everyday Life. Cambridge: Cambridge University Press.

Tajfel, Henri. 1978. Social categorization, social identity and social comparison. In: Tajfel, Henri (ed.) Differentiation between Social Groups: Studies in the social psychology of Intergroup Relations, 61-76. London: Academic Press.

Terkourafi, Marina. 2008. Toward a unified theory of politeness, impoliteness and rudeness. In: Bousfield, Derek and Miriam Locher (eds.), Impoliteness in language: Studies on its interplay with power in theory and practice, 45-74. Berlin \& New York: Mouton de Gruyter.

Wee, Lionel. 2004. 'Extreme Communicative Acts' and the boosting of illocutionary force. Journal of Pragmatics 36 (12): 2161-2178.

Yaratan H., Yucesoylu R. 2010. Self-esteem, self-concept, self-talk and significant others' statements in fifth grade students: Differences according to gender and school type. Procedia - Social and Behavioral Sciences 2: 3506-3518. 